\title{
Saturated Fatty Acid Increases Lung Macrophages and Augments House Dust Mite-Induced Airway Inflammation in Mice Fed with High-Fat Diet
}

\author{
Hiroki Tashiro, ${ }^{1}$ Koichiro Takahashi ${ }^{1,3}$ Hironori Sadamatsu, ${ }^{1}$ Go Kato, ${ }^{1}$ Keigo Kurata, \\ Shinya Kimura, ${ }^{1}$ and Naoko Sueoka-Aragane ${ }^{1}$
}

\begin{abstract}
Obesity is one of the phenotypes of severe asthma, which is considered to be a heterogeneous syndrome; however, its interaction with airway inflammation is not fully understood. The aim of this study was to clarify the role of saturated fatty acids in augmenting airway inflammation induced by house dust mite (HDM) in obesity. Subjects were Balb/c mice fed a high-fat diet (HFD) for 10 weeks, followed by sensitization and exposure to HDM. Subjects were also administered palmitic acid (PA) for 4 weeks with concurrent sensitization and exposure to HDM. Airway inflammation was assessed by quantifying the amount of inflammatory cells in bronchoalveolar lavage (BAL) and airway resistance was measured. In vitro, lipopolysaccharide (LPS)-primed macrophages were stimulated by PA. The amount of monocyte chemoattractant protein-1 (MCP-1), interleukin-1 $\beta$ (IL-1 $\beta$ ), and tumor necrosis factor $\alpha(\mathrm{TNF}-\alpha)$ was examined in the supernatant. Compared to normal chow mice, HFD mice underwent significant increases in body weight; increases in number of lung macrophages, including circulating monocytes and alveolar macrophages; and increases in bronchoalveolar lavage fluid (BALF) total cell count, including neutrophils but not eosinophils, after HDM sensitization and exposure. In vitro, PA induced MCP-1 and augmented LPS-primed production of IL- $1 \beta$ and TNF- $\alpha$ in macrophages. Among HDM mice that were administered PA, there was an increase BALF total cell count, including neutrophils but not eosinophils, compared to vehicle mice. In conclusion, saturated fatty acid increased the number of lung macrophages and augmented HDM-induced neutrophilic airway inflammation in a HFD mouse model.
\end{abstract}

KEY WORDS: bronchial asthma; obesity; high-fat diet; house dust mite; saturated fatty acid; macrophages.

\section{INTRODUCTION}

Bronchial asthma is a common respiratory disease that involves eosinophilic airway inflammation induced by sensitization and exposure to antigens, such

\footnotetext{
${ }^{1}$ Division of Hematology, Respiratory Medicine and Oncology, Department of Internal Medicine, Faculty of Medicine, Saga University, 5-1-1 Nabeshima, Saga, 849-8501, Japan

${ }^{2}$ Institute of Tokyo Environmental Allergy, Tokyo, Japan

${ }^{3}$ To whom correspondence should be addressed at Division of Hematology, Respiratory Medicine and Oncology, Department of Internal Medicine, Faculty of Medicine, Saga University, 5-1-1 Nabeshima, Saga, 8498501, Japan. E-mail: takahak@cc.saga-u.ac.jp
}

as house dust mite (HDM) [14, 23]. Inhaled corticosteroid (ICS), which is the principal medication for the treatment of asthma, has contributed to disease control and reduction of mortality for the past 20 years [47]. However, $5 \%$ to $10 \%$ of cases that are refractory to standard treatment are identified as severe asthma [8, $27,35]$. Severe asthma is characterized by uncontrolled symptoms, frequent exacerbations, airflow limitation, and airway inflammation $[28,46]$. As a result, patients with severe asthma need higher cost of medical treatment than those with mild asthma $[1,2]$. Severe asthma is considered to be a heterogeneous syndrome that has features of early-onset atopic factor, late-onset 
eosinophilic airway inflammation, neutrophilic airway inflammation, and obesity [35, 46]. Basic as well as clinical research has shown that obesity is an important phenotype of severe asthma [3, 20, 34, 38]. In addition, asthmatic patients who are obese do not respond as well to ICS as patients with normal body mass index (BMI) $[4,33,39]$. In fact, weight loss was shown to improve airway hyperresponsiveness (AHR) and symptom control in obese asthmatic patients [11, 12]. These studies implied that the extent of obesity and the severity of asthma are closely related; however, the interaction between obesity and the pathogenesis of asthma, including airway inflammation, is not fully understood.

Obesity itself is considered an inflammatory disease [45] that is associated with other low-grade systemic inflammatory diseases, such as metabolic syndrome, type 2 diabetes, non-alcoholic fatty liver, and cardiovascular disease [17, 43]. In previous studies, animal models were administered a high-fat diet (HFD) to induce obesity so that the interaction between obesity and inflammation could be analyzed [15, 18, 22]. Overconsumption of saturated fatty acids (SFA), which compose a HFD, was discovered to be a risk factor for obesity-related diseases [13, 37]. SFA induces inflammatory molecules, such as tumor necrosis factor $\alpha$ (TNF- $\alpha$ ), interleukin (IL)-1 $\beta$, IL-6, monocyte chemoattractant protein-1 (MCP-1), and macrophage inhibitory factor through toll-like receptor 4 (TLR4) $[36,44,52]$, and regulates organ inflammation through macrophage recruitment $[9,50]$. According to these data, increased amount of SFA in obese individuals would lead to inflammation in various organs.

In the present study, an increased number of lung macrophages were observed in a HFD mouse model. HDM-induced mice with augmented neutrophilic airway inflammation and AHR were found to have elevated levels of IL-17A and macrophage inflammatory protein 2 (MIP2) after receiving a HFD for 10 weeks. Palmitic acid (PA), which is the main SFA component of HFD, directly induced inflammatory cytokine and chemokine production from macrophages. Finally, we demonstrated that similar to administration of HFD, administration of PA to mice increased the number of lung macrophages and augmented HDM-induced neutrophilic airway inflammation and AHR. To the best of our knowledge, this was the first report that demonstrated SFA-augmented pathogenesis of asthma in an obese mouse model; this observation was associated with lung macrophages, which are likewise considered to enhance the mechanism of obese asthma.

\section{MATERIALS AND METHODS}

\section{Allergen and Chemicals}

HDM extracts from Dermatophagoides farinae (Der f) were purchased from ITEA Inc. (Tokyo, Japan). PA (Sigma-Aldrich, Saint Louis, MO, USA) was dissolved in $50 \%$ ethanol at $60{ }^{\circ} \mathrm{C}$ to yield a 50 -mM stock concentration, which was kept at $-20{ }^{\circ} \mathrm{C}$. PA was diluted to the appropriate concentration using $1 \%$ fatty acid-free bovine serum albumin (BSA) at $37{ }^{\circ} \mathrm{C}$. The endotoxin level in the PA solution was less than the detection limit of $0.0015 \mathrm{EU} / \mathrm{ml}$ by the assay kit (Limulus ES-2, Wako, Japan).

\section{Mice}

Female BALB/c mice (Japan SLC Inc.; Hamamatsu, Japan) aged 3-6 weeks were kept at the Saga University animal facility under specific pathogen-free conditions. Animal experiments were undertaken following the guidelines for care and use of experimental animals by the Japanese Association for Laboratory Animals Science (1987) and were approved by the Saga University Animal Care and Use Committee.

\section{Administration of High-Fat Diet and Palmitic Acid}

Starting at 3 weeks of age, female mice were fed with either normal chow or an HFD for 10 weeks. The HFD (D12492; Research Diets Inc., New Brunswick, $\mathrm{NJ}$ ) provided $60 \%$ of energy in the form of fat. At the age of 6 weeks, BSA or $50-\mu \mathrm{M}(150 \mu \mathrm{l})$ palmitateBSA complex was administered by intraperitoneal injection five times per week for 4 weeks. Body weight was measured every week.

\section{Protocol for House Dust Mite-Induced Airway Inflam- mation in Mice Administered with High-Fat Diet or Palmitic Acid}

In the HFD model, mice aged 3 weeks were fed normal chow or HFD for total 10 weeks. After 7 weeks of HFD intake, mice were sensitized by intranasal administration of $25 \mu \mathrm{g}$ HDM or phosphate-buffered saline (PBS) once a week for 3 weeks. At 10 weeks of HFD intake, mice were exposed to continuous 
intranasal administration of $5 \mu \mathrm{g}$ HDM or PBS for 3 days. In the PA mouse model aged 6 weeks, $50 \mu \mathrm{M}(150 \mu \mathrm{l})$ of palmitate-BSA complex or a BSA vehicle was administered by intraperitoneal injection five times per week for 4 weeks. Sensitization was done by intranasal administration of $25 \mu \mathrm{g}$ HDM or a vehicle on days 2, 9, and 16. Exposure was carried out by intranasal administration of $5 \mu \mathrm{g}$ HDM or a vehicle on days 23,24 , and 25 . On days with simultaneous PA and HDM administration, PA was given $30 \mathrm{~min}$ before HDM inoculation. For all these models, mice were euthanized by intraperitoneal injection of sodium pentobarbital $24 \mathrm{~h}$ after the final exposure. Bronchoalveolar lavage fluid (BALF) and lung tissue were collected for further analyses.

\section{Isolation of Single Cells from Lung Tissue}

Peripheral lung tissue was cut into small pieces then transferred through a $70-\mu \mathrm{m}$ mesh before processing in a digestion buffer that included deoxyribonuclease I (Invitrogen, Waltham, MA) and collagenase type 2 (Worthington Inc., Lakewood, NJ). The remaining red cells were lysed using BD Pharm Lysis (BD Biosciences, San Jose, $\mathrm{CA}$ ) to obtain single-cell suspensions.

\section{Flow Cytometry}

Single-cell suspensions were pre-incubated with Fc $\gamma$ R-specific blocking $\mathrm{mAb}$ and washed before staining. Cells were stained with CD11b, CD11c, CD45, and Ly6c (eBioscience, San Diego, CA) before collection on a flow cytometer (FACS Aria 2; BD Bioscience, Franklin Lakes, NJ) and analysis by FlowJo 8.3.3 software (Tree Star, Ashland, OR).

\section{Collection of Bronchoalveolar Lavage Fluid}

BALF samples were collected, as described previously [21,40]. Briefly, a 20-G tube was inserted in the trachea, followed by two times of lung lavage with $1 \mathrm{ml}$ of saline. The cell suspension was centrifuged at $100 \times g$ for $5 \mathrm{~min}$ at $4{ }^{\circ} \mathrm{C}$. The total number of cells was counted using a hemocytometer. Cytospin samples were prepared from the cell suspension. Cell differentiation was determined by counting at least 300 leukocytes in samples stained with Diff-Quik (Siemens, Germany).

\section{Airway Hyperresponsiveness to Methacholine}

Briefly, mice were anesthetized with pentobarbital before insertion of an 18-G metal needle into an exposed trachea, which was connected to a forced oscillation technique (flexiVent system; SCIREQ Inc., Montreal, Canada). Next, their lungs were inflated to a pressure of $30 \mathrm{cmH}_{2} \mathrm{O}$; baseline recordings were obtained using a single frequency $(2.5 \mathrm{~Hz}, 1.2 \mathrm{~s}$; Snapshot-150) and a broadband low frequency $(1-20.5 \mathrm{~Hz}$, $3 \mathrm{~s}$; Quick-Prime-3). The mice were then exposed to an aerosol of PBS. All parameters calculated from both test signals were recorded alternately every $10 \mathrm{~s}$ for 3 min. Finally, two deep lung inflations were given. The above protocol was repeated for five times more with aerosols containing sequentially increasing concentrations of $0.1,1.0,10,20$, and $50 \mathrm{mg} / \mathrm{ml}$ methacholine (Sigma-Aldrich, Japan).

\section{Hematoxylin-Eosin and Periodic Acid-Schiff Histology Examination}

Histologic examination was performed, as previously reported [16]. Lungs were fixed with $10 \%$ neutral-buffered formalin (Wako, Japan) and embedded in paraffin. Lung sections were stained with hematoxylin and eosin (H\&E) and periodic acid-Schiff (PAS).

\section{Preparation of Lung Homogenates}

After BAL, the left lung was isolated and homogenized in 50-mM Tris-buffered saline ( $\mathrm{pH}$ 7.4) containing $1 \mathrm{mM}$ ethylenediaminetetraacetic acid, $1 \mathrm{mM}$ phenylmethylsulfonyl fluoride, $1 \mu \mathrm{g} / \mathrm{ml}$ aprotinin, $1 \mu \mathrm{g} / \mathrm{ml}$ leupeptin, $1 \mathrm{mM}$ $\mathrm{Na}_{3} \mathrm{VO}_{4}$, and $1 \mathrm{mM} \mathrm{NaF}$. The lung homogenates were centrifuged at $10,000 \times g$ for $15 \mathrm{~min}$; supernatants were collected and stored at $-80^{\circ} \mathrm{C}$ until needed.

\section{Quantification of Cytokines Using Enzyme-Linked Immunosorbent Assay}

IL-13, TNF- $\alpha$, IL-1 $\beta$, IL-17A, MCP-1, and MIP2 were measured using enzyme-linked immunosorbent assay (ELISA) Kits (R\&D Systems Inc., Minneapolis, MN), according to the manufacturers' instructions. All samples were tested in duplicate.

\section{Cell Culture of RAW 264.7, Bone Marrow Macrophages, and Peritoneal Macrophages}

RAW 264.7 was grown in an RPMI 1640 medium containing $10 \%$ fetal calf serum (FCS). Bone marrow (BM) cells were isolated from BALB/c mice, as previously reported [41], and were suspended at $1.0 \times 10^{6}$ cells/ml in RPMI 1640 medium supplemented with $10 \%$ FCS. The cells were cultured in the presence of 
$10 \mathrm{ng} / \mathrm{ml}$ recombinant murine macrophage colonystimulating factor (M-CSF) (R\&D Systems Inc., Minneapolis, MN) at $37{ }^{\circ} \mathrm{C}$ in a humidified atmosphere containing 5\% carbon dioxide for 6 days. On day 6 , cells were harvested and cultured as BM-derived macrophages (BMMs). To obtain fresh peritoneal macrophages, mice were injected intraperitoneally with $1 \mathrm{ml}$ thioglycollate (3\%). After 4 days, peritoneal fluid was obtained by lavage with $10 \mathrm{ml}$ PBS. The fluid was centrifuged to isolate peritoneal macrophages, which were re-suspended in RPMI 1640 medium. These cells were cultured at a density of $1 \times 10^{6}$ cells in RPMI 1640 containing FCS and were stimulated as indicated in Fig. 3. RNA was isolated after $8 \mathrm{~h}$ and the supernatant was analyzed by ELISA after $24 \mathrm{~h}$.

\section{RNA Extraction and Quantitative PCR}

RNA was extracted from RAW 264.7 using the RNeasy Protect Mini Kit (QIAGEN, Netherlands); assessed by quantity and quality using a NanoDrop 1000A spectrophotometer (NanoDrop Products, Wilmington, DE, USA); and was reverse transcribed to cDNA. Taqman gene expression assays were used to detect TLR4 (Mm00445273-m1 Tlr4) and 18S RNA (Mm03928990-g1 Rn18s). Messenger RNA expression levels were standardized using 18S RNA expression.

\section{Statistical Analysis}

Data were presented as mean \pm standard deviation (SD). Differences between two groups were analyzed by Student's t test. Multiple comparisons of continuous variables were analyzed using one-way analysis of variance, followed by a post hoc Tukey-Kramer test for multiple groups. Significance was set at a $p$ value of 0.05 .

\section{RESULTS}

\section{High-Fat Diet Increased Body Weight and Lung Macrophages but Not Airway Inflammation and Hyperresponsiveness}

To clarify the interaction between obesity and asthma, we initially focused on the lung cell population of HFD mice (Fig. 1a). The body weight of HFD mice significantly increased compared with that of normal chow mice (Fig. 1b). The appearance of HFD mice is shown in Fig. 1c. To identify the lung cell population
Fig. 1. HFD increases body weight and number of lung macrophages. a Protocol of feeding normal chow or HFD to mice for 10 weeks. Comparison of $\mathbf{b}$ body weight gain ( $n=6$ in each group) and $\mathbf{c}$ representative pictures of normal chow and HFD mice. $\mathbf{d}$ Cells are identified from digested lungs; after exclusion of doublets and debris, leukocytes are separated by CD45 staining. CD11c-negative, CD11b-positive, and Ly6c-positive cells are identified on circulating monocytes. On the other hand, CD11cpositive and CD11b-negative cells are identified on alveolar macrophages. The percentages of $\mathbf{e}$ circulating monocytes and $\mathbf{f}$ alveolar macrophages are compared between normal chow and HFD mice. $* * P<0.01$. HFD, high-fat diet.

in HFD mice, we examined single-cell suspensions by flow cytometry (Fig. 1d). Lung macrophages were classified as recruited monocytes from the systemic circulation (circulating monocytes) or resident macrophages (alveolar macrophages). In the analysis, circulating monocytes and alveolar macrophages were significantly increased in the lungs of HFD mice compared with normal chow mice (Fig. 1e, f). Circulating monocytes were characterized by the surface markers $\mathrm{CD}_{4} 5^{+} ; \mathrm{CD} 11 \mathrm{c}^{-} ; \mathrm{CD}_{11 \mathrm{~b}^{+}}$; and $\mathrm{Ly}_{6 \mathrm{c}^{+}}$; whereas as alveolar macrophages were $\mathrm{CD} 45^{+} ; \mathrm{CD} 11 \mathrm{c}^{+}$; and $\mathrm{CD}_{11 \mathrm{~b}}{ }^{-}$. The total cell count and differential count in BALF were not different between HFD mice and normal chow mice. AHR also showed no difference between these groups (data not shown). These results suggested that HFD increased the number of lung macrophages, including circulating monocytes and alveolar macrophages, but not airway inflammation and AHR.

\section{High-Fat Diet Augmented House Dust Mite-Induced Neutrophilic Airway Inflammation, Airway Hyperresponsivenes, and Cytokine Production in the Lungs}

We investigated the association of HFD with airway inflammation, AHR, and cytokine level in HDM-induced mice (Fig. 2a). The body weights of PBS-HFD and HDMHFD mice were significantly higher than those of PBSchow and HDM-chow mice (Fig. 2b). BALF total cell count, neutrophils, and eosinophils were significantly higher in HDM-chow and HDM-HFD mice than in PBSchow and PBS-HFD mice (Fig. 2c). Additionally, among the HDM mice, the BALF total cell count and neutrophils, not eosinophils, were significantly increased in HFD mice compared to chow mice (Fig. 2c). Airway resistance, represented by AHR, was higher in HDM-chow mice than in PBS-chow and PBS-HFD mice and was significantly higher in HDM-HFD mice than in HDM-chow mice (Fig. 2d). 
(a)

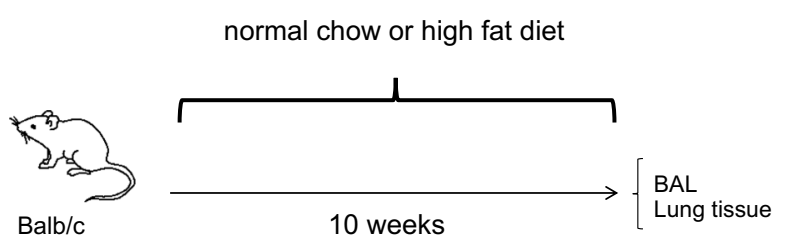

(c)

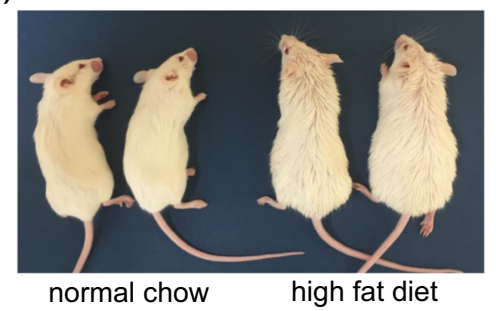

(b)

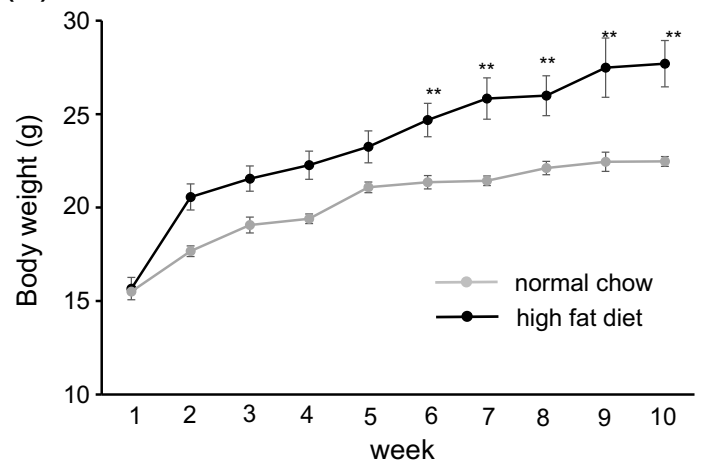

(d)
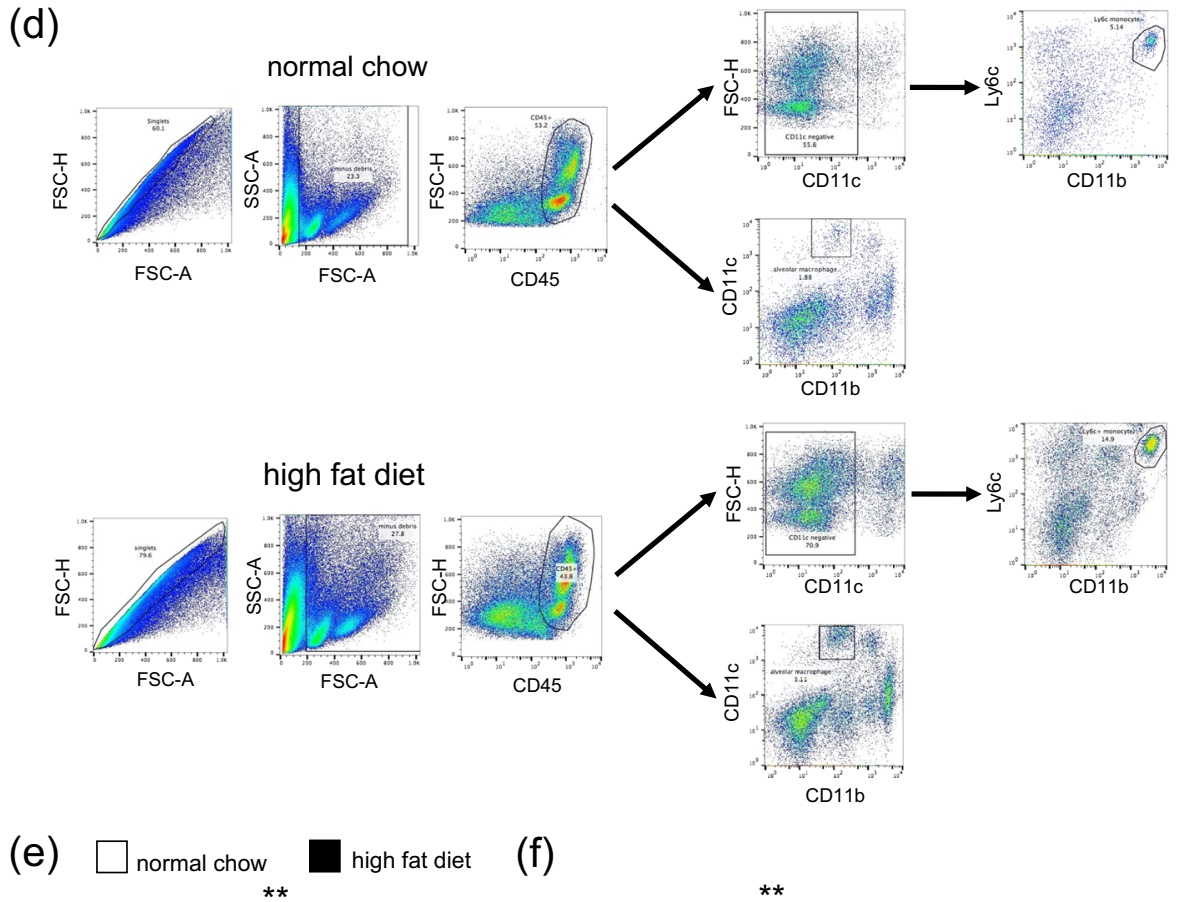

(f)
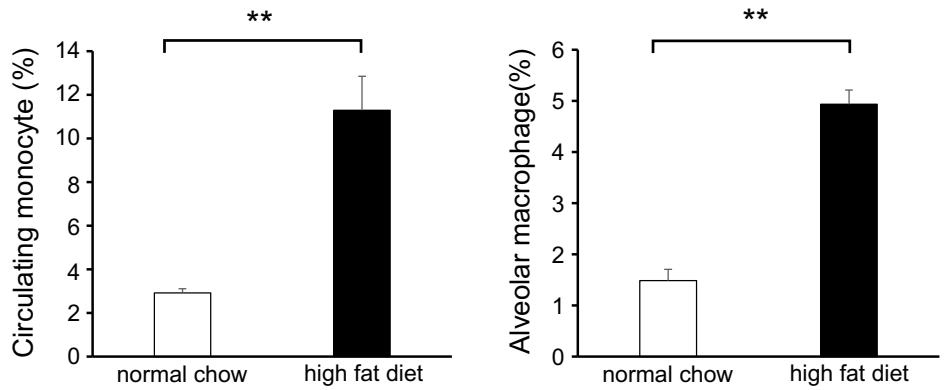
(a)
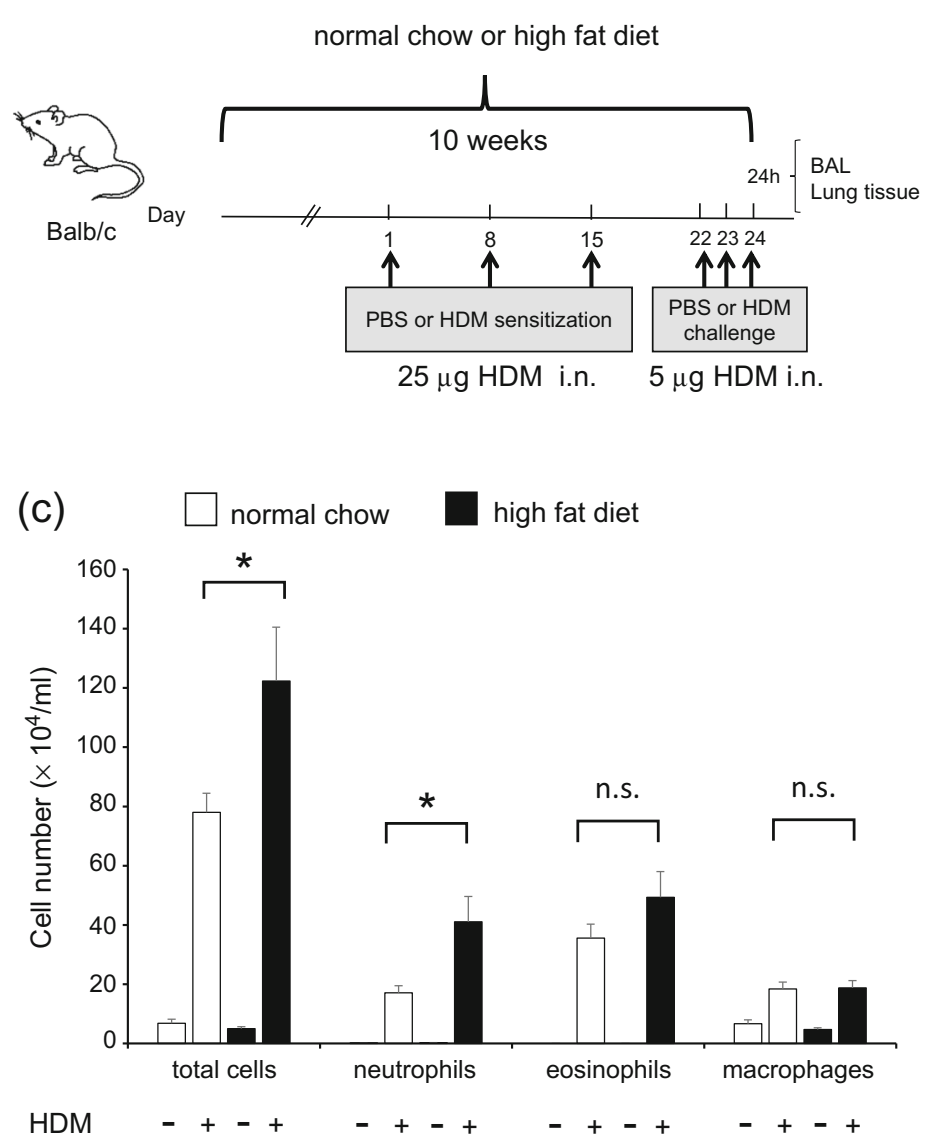

(b)

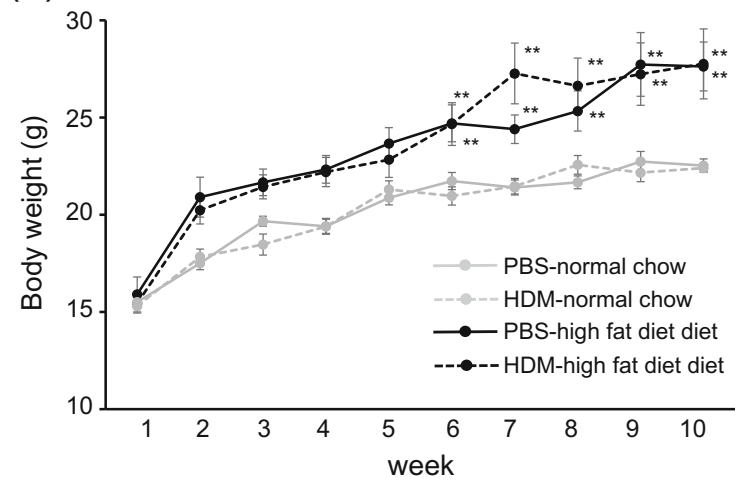

(d)

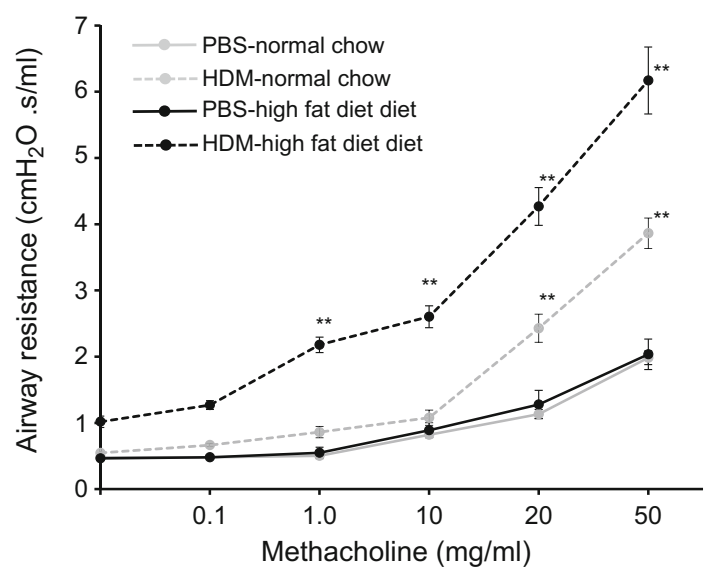

Fig. 2. HFD augments HDM-induced neutrophilic airway inflammation, airway hyperresponsiveness, and cytokine production in the lungs. a Protocol of HDM-induced airway inflammation in normal chow or HFD mouse model. b Body weight gain is compared among PBS-chow, HDM-chow, PBS-HFD, and HDM-HFD mice ( $n=6$ in each group). $\mathbf{c}$ Bronchoalveolar lavage fluid analysis for total and differential cell counts among PBS-chow, HDM-chow, PBSHFD, and HDM-HFD mice ( $n=6$ in each group). The HDM-HFD group is compared with the HDM-chow group. d Airway hyperresponsiveness is measured through assessment of airway resistance according to graded concentrations of methacholine in PBS-chow, HDM-chow, PBS-HFD, and HDMHFD mice ( $n=6$ in each group). The HDM-chow group is compared with the PBS-chow group, while the HDM-HFD group is compared with HDM-chow mice. e Histologic examination for airway inflammation. Sections are stained with $\mathrm{H} \& \mathrm{E}$ (upper panels) and PAS (lower panels). Original magnification was $\times 200$. Concentrations of f IL-13, g IL-17A, h IL-1 $\beta$, and i MIP2 in lung tissue are measured by ELISA $(n=6$ in each group). $* P<0.05, * * P<0.01 . H F D$, high-fat diet; $H D M$, house dust mite; $P B S$, phosphate-buffered saline; $H \& E$, hematoxylin and eosin; $P A S$, periodic acid-Schiff; $M I P 2$, macrophage inflammatory protein 2; ELISA, enzyme-linked immunosorbent assay.

On pathologic examination of the lungs, inflammatory cells and goblet cell hyperplasia were intensely seen in HDM-normal chow mice and HDM-HFD mice compared with PBS-chow mice and PBS-HFD mice. The findings in HDM-HFD mice tended to be more intense than those in HDM-chow mice (Fig. 2e). The levels of cytokines IL-13, IL-17A, IL-1 $\beta$, and MIP2 in lung tissue were increased in HDM-chow and HDMHFD mice compared with PBS-chow and PBS-HFD mice. IL-17A and MIP2, but not IL-13 and IL-1 $\beta$, were significantly increased in the lungs of HDMHFD mice compared with those of HDM-chow mice. According to these data, HDM-induced neutrophilic airway inflammation, AHR, and production of IL17A and MIP2 cytokines in the lungs were augmented by an HFD, probably by increase in the number of lung macrophages, which might be related to the progression of airway inflammation. 
(e)

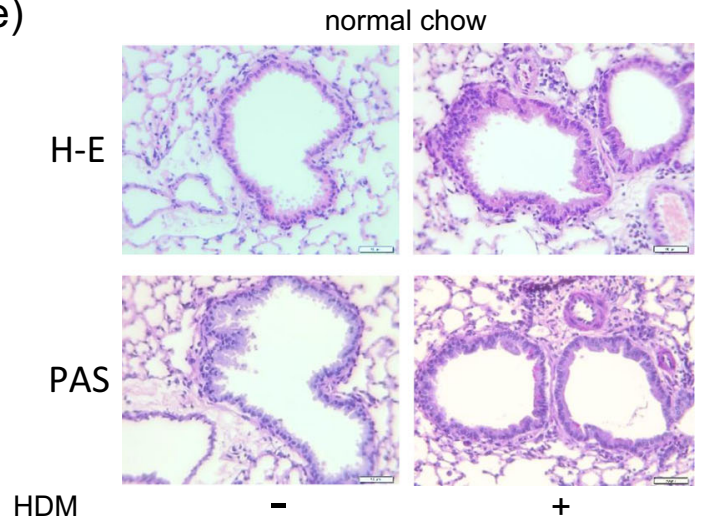

(f) $\square$ normal chow high fat diet

n.s.

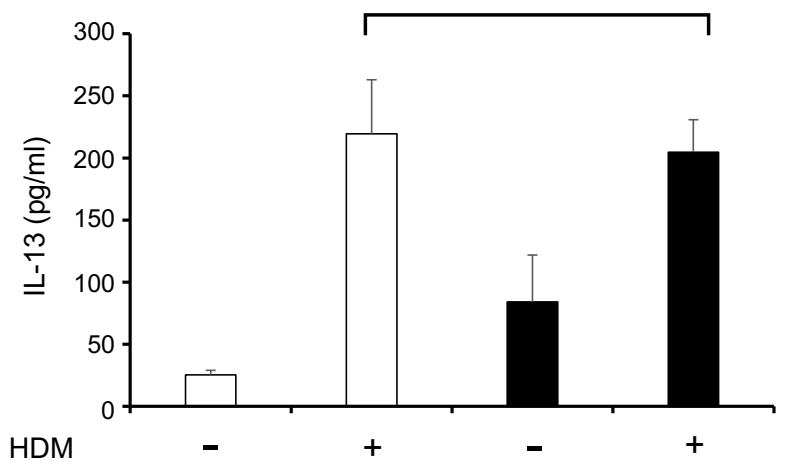

(h)

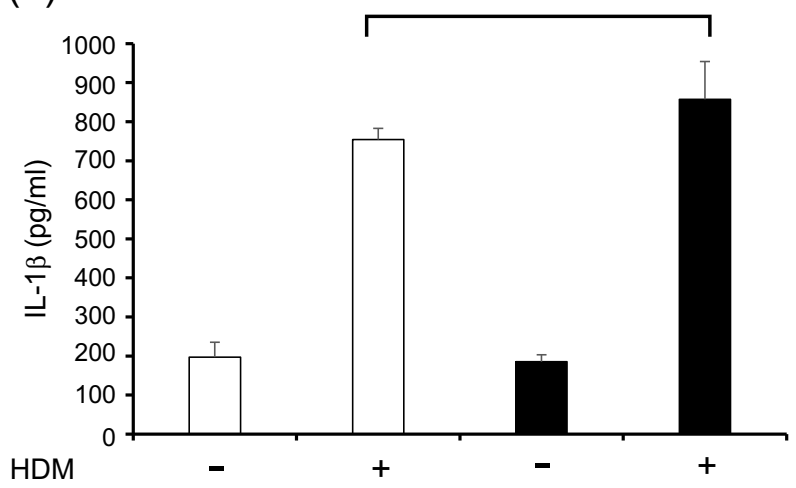

Fig. 2. continued.

Saturated Fatty Acids Induced In Vitro Monocyte Chemoattractant Protein-1 and LipopolysaccharidePrimed Inflammatory Cytokine Production from Macrophages

To clarify the presence of a direct interaction between HFD and macrophages, we used in vitro assays of SFA and
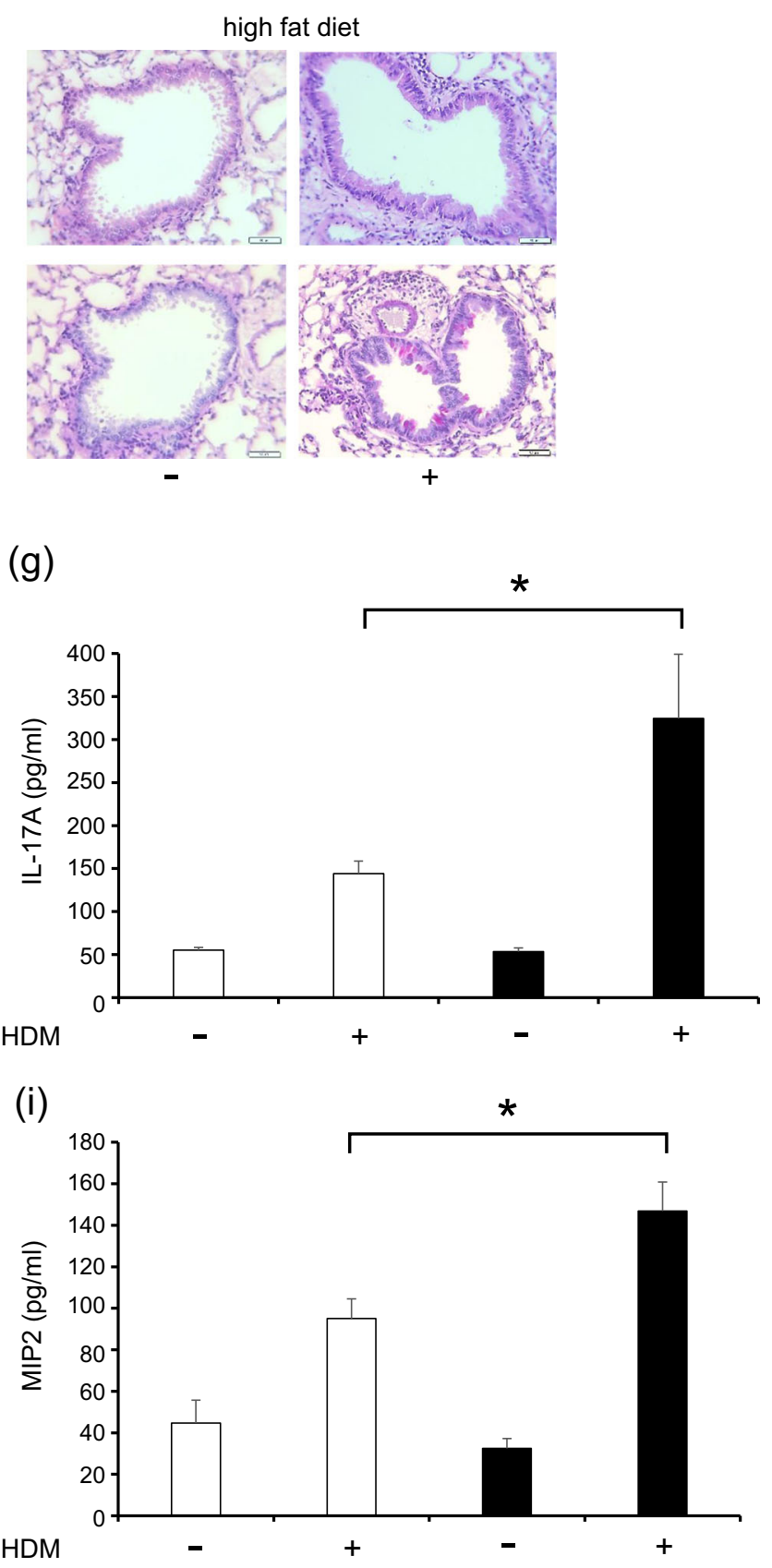

several macrophages. In an official analysis of the fatty acid profile of HFD, 37.1\% comprised SFA, of which PA was the most common at $62.2 \%$. Therefore, we used PA to represent SFA and found that it induced the expression of TLR4 and increased MCP-1 in RAW cells (Fig. 3a, b). Because HDM did not induce cytokine production from macrophages 
(a)

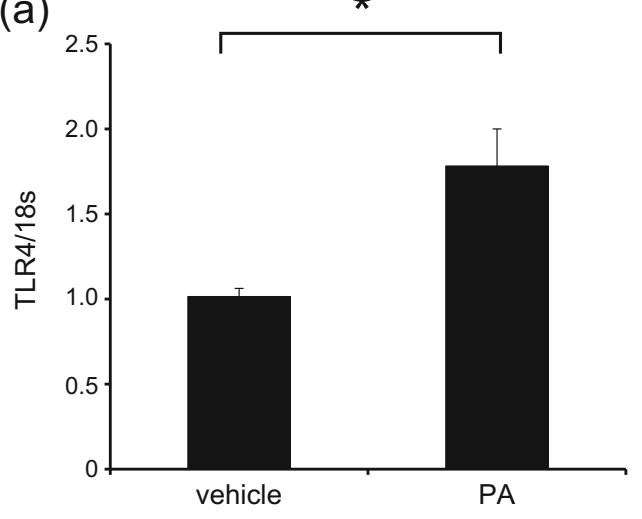

(c)

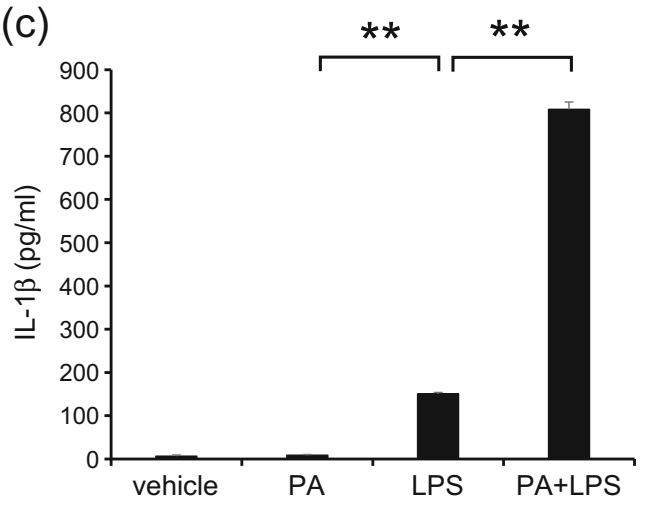

(e)

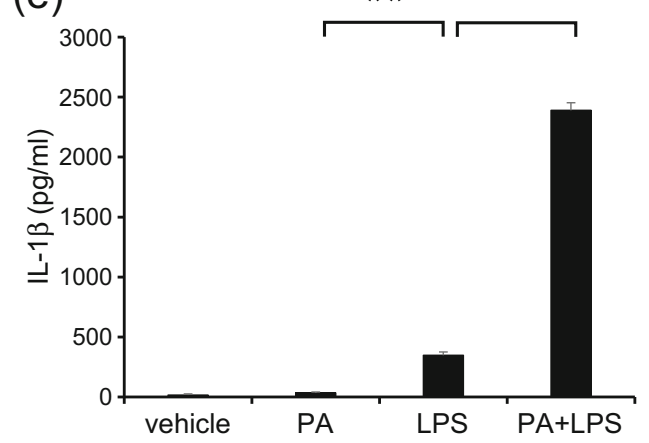

(g)

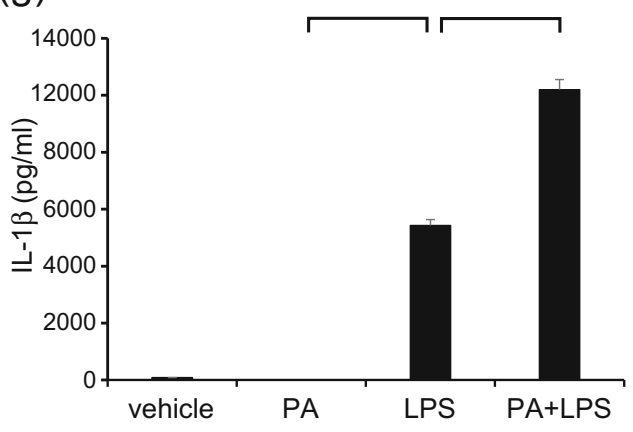

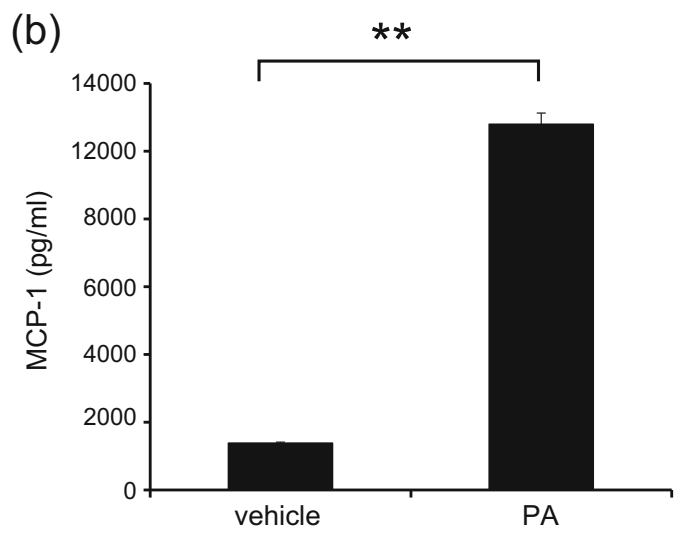
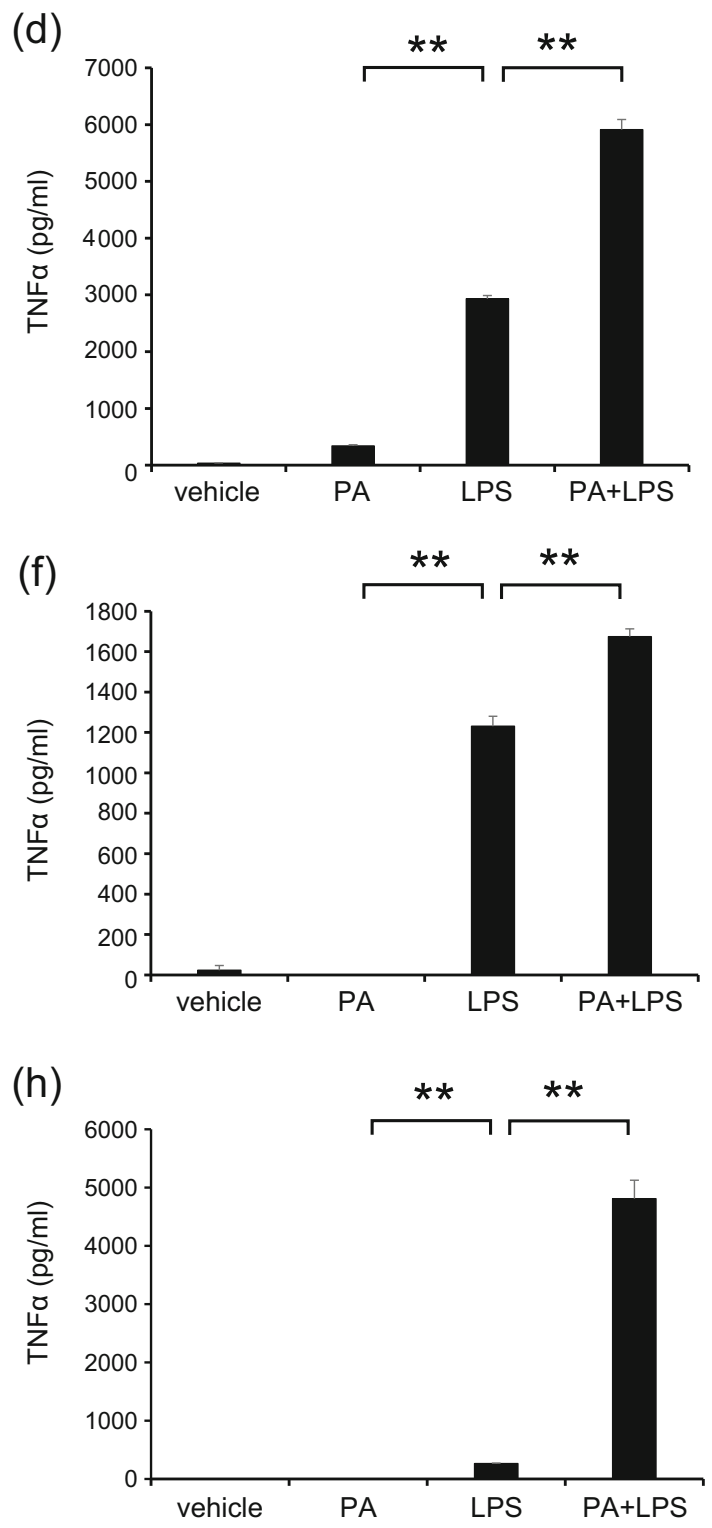
Fig. 3. PA induces TLR4 expression, MCP-1, and LPS-primed inflammatory cytokine production from macrophages in vitro. RAW 264.7 are stimulated by PA $(500 \mu \mathrm{M})$ for $8 \mathrm{~h}$ to isolate RNA. RAW 264.7, BMMs, and peritoneal macrophage are stimulated for $24 \mathrm{~h}$ by PA $(500 \mu \mathrm{M})$ and LPS $(100 \mathrm{pg} / \mathrm{ml})$ to major protein level by ELISA. For cells cultured with both PA and LPS, PA is pre-incubated $1 \mathrm{~h}$ before stimulation by LPS. a TLR4 level in RAW 264.7 was measured by real-time RT-PCR assay. The concentrations of $\mathbf{b}$ MCP-1, $\mathbf{c}$ IL- $1 \beta$, and $\mathbf{d}$ TNF- $\alpha$ in the supernatant of RAW; $\mathbf{e}$ IL- $1 \beta$ and $\mathbf{f}$ TNF- $\alpha$ in the supernatant of BMMs; and $\mathbf{g}$ IL- $1 \beta$ and h TNF- $\alpha$ in the supernatant of peritoneal macrophages are shown. The LPS-stimulated group is compared with the PA-stimulated group, while the PA+LPS-stimulated group is compared with the LPS-stimulated group. The results are representatives of two independent experiments. $*_{*} P<0.01$. TLR4, toll-like receptor 4; BMMs, bone marrow derived macrophages; $P A$, palmitic acid; $L P S$, lipopolysaccharide; $M C P-1$, monocyte chemoattractant protein-1; TNF- $\alpha$, tumor necrosis factor $\alpha$.

in vitro (data not shown), we cultured macrophages with PA and LPS instead. LPS increased the levels of TNF- $\alpha$ and IL$1 \beta$ in RAW cells (Fig. 3c, d), BMMs (Fig. 3e, f), and peritoneal macrophages (Fig. $3 \mathrm{~g}, \mathrm{~h}$ ); these levels were significantly increased further by pre-incubation with PA. These data suggested that SFA induced TLR4 expression and macrophage recruitment and directly augmented LPSrelated inflammation. SFA was considered a factor that affected airway inflammation in HDM-HFD mice.

\section{Saturated Fatty Acid Administration Increased Lung Macrophages but Not Airway Inflammation and Airway Hyperresponsiveness in Mice}

We administered PA intraperitoneally to mice [13, 26] and investigated the cell population in the lungs (Fig. 4a). The body weights of PA-administered mice and vehicle mice were not different (data not shown). Circulating monocytes and alveolar macrophages were significantly increased in the lungs of PA-administered mice compared with those in vehicle mice (Fig. 4b-d). BALF total cell count and differential count, as well as AHR, were not different between PA-administered mice and vehicle mice (data not shown). These data suggested that similar to HFD, PA increased the number of lung macrophages, including circulating monocytes and alveolar macrophages, without airway inflammation and AHR.

\section{Saturated Fatty Acids Augmented House Dust Mite- Induced Neutrophilic Inflammation, Airway Hyperresponsiveness, and Cytokine Levels in the Lungs}

Finally, we sensitized and exposed PA-administered mice with HDM to identify the role of SFA in the pathogenesis of asthma (Fig. 5a). Body weight did not differ among PBS-vehicle mice, HDM-vehicle mice, PBS-PA mice, and HDM-PA mice (data not shown). BALF total cell count, neutrophils, and eosinophils were significantly higher in HDM-vehicle and HDM-PA mice than in PBS-vehicle mice and PBS-PA mice (Fig. 5b). Total cell count and neutrophils were significantly increased in the BALF of HDM-PA mice compared with those in HDM-vehicle mice. Eosinophils tended to be increased in HDM-PA mice than in HDM-vehicle mice; however, this was not significantly different (Fig. 5b). Airway resistance was higher in HDM-vehicle mice than in PBS mice and further increased significantly in HDMPA-administered mice than in HDM-vehicle mice (Fig. 5c).

On pathologic examination of the lungs, the presence of inflammatory cells and goblet cell hyperplasia was more intense in HDM-vehicle mice and HDM-PAadministered mice than in PBS-vehicle mice and PBSPA-administered mice. The findings in HDM-PAadministered mice tended to be more intense than those in HDM-control mice (Fig. 5d). IL-13, IL-17A, IL-1 $\beta$, and MIP2 cytokines in lung tissue were increased in HDM-vehicle mice and HDM-PA-administered mice compared to PBS-vehicle mice and PBS-PAadministered mice. IL-13 and IL-17A tended to be higher in the lungs of HDM-PA-administered mice than in HDM-vehicle mice, but this was not statistically significant (Fig. 5e, f). IL-1 $\beta$ and MIP2 significantly increased in the lungs of HDM-PA-administered mice compared to HDM-vehicle mice (Fig. 5g, h).

\section{DISCUSSION}

The present study demonstrated that SFA had important roles in the augmenting the mechanisms of asthma in obesity. Specifically, these roles included progression of neutrophilic airway inflammation and AHR. HFD, which comprised a large amount of SFA, increased the number of macrophages in the lungs and exacerbated neutrophilic airway inflammation and AHR. This observation was associated with elevation in the levels of IL-17A and MIP2 cytokines in the lungs. Moreover, intraperitoneal administration of SFA showed similar effects with HFD mice in increasing lung macrophages and progression of HDMinduced neutrophilic airway inflammation and AHR, along with increased IL-1 $\beta$ and MIP 2 cytokines in the lungs. PA affected not only MCP-1 induction but also TNF- $\alpha$ and IL$1 \beta$ production and TLR 4 upregulation in macrophages. To 
(a)

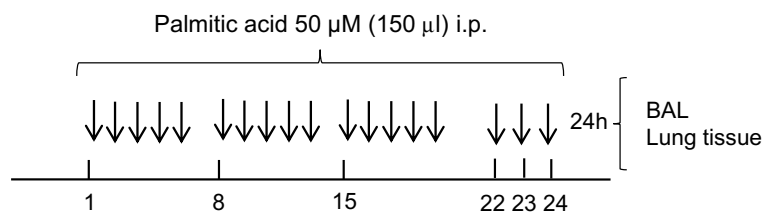

(b)
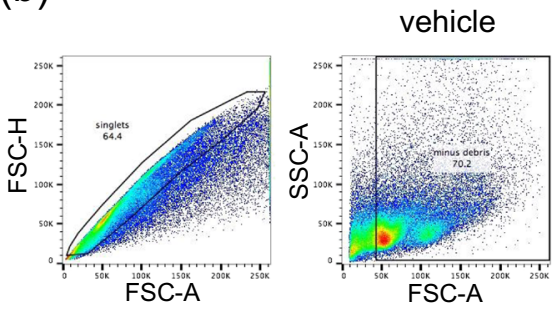

palmitic acid

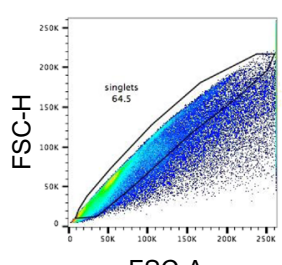
FSC-A

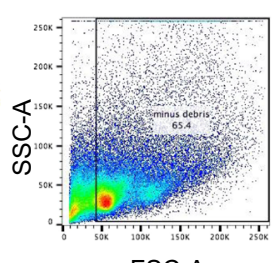

FSC-A

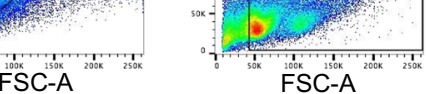
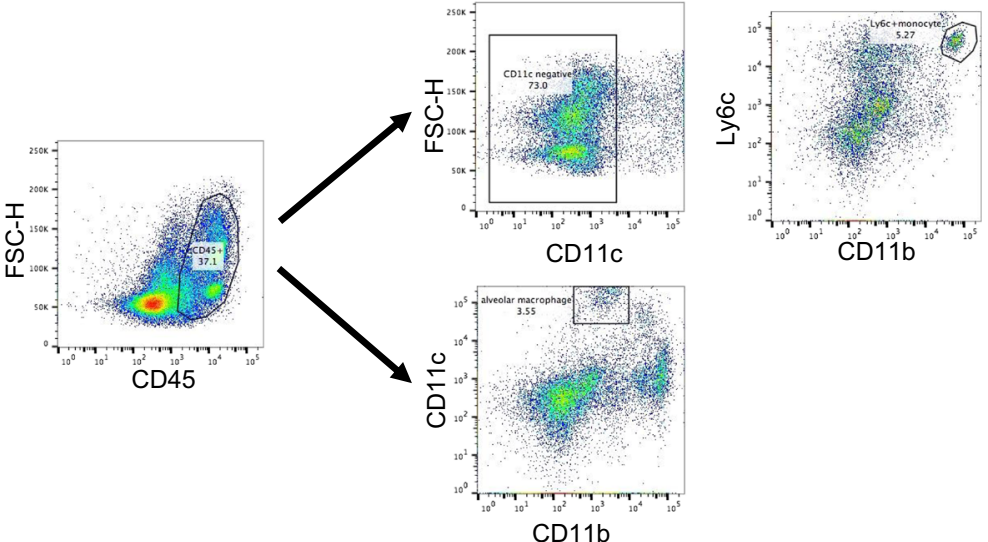

CD11b
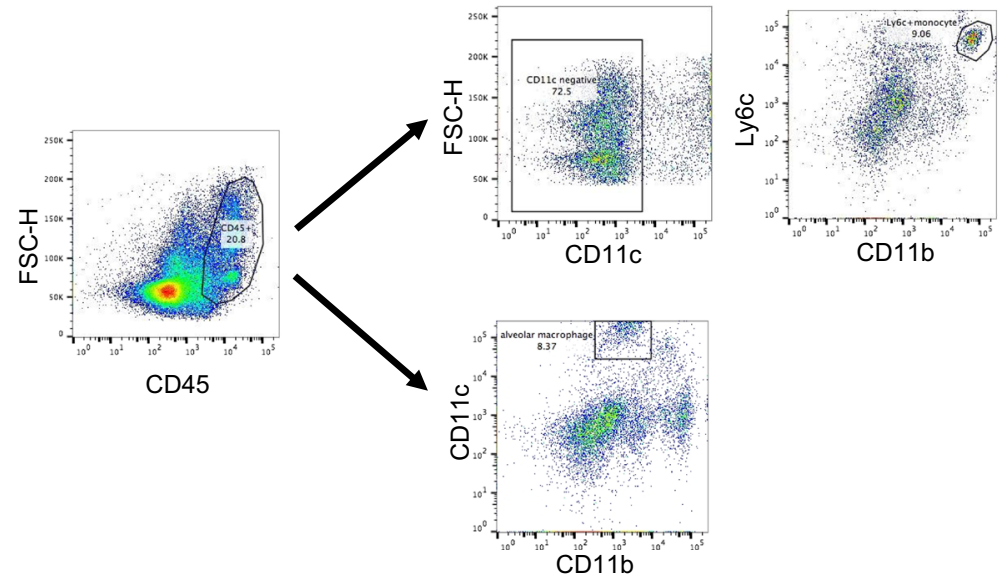

(d)

(c) $\square$ vehicle palmitic acid

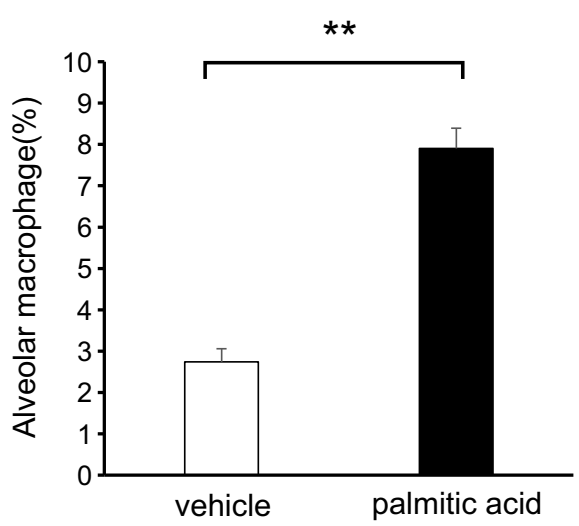


Fig. 4. Palmitic acid increases lung macrophages. a Protocol of vehicleor palmitic acid- $(50 \mu \mathrm{M})$ administered mouse model. b Cells are identified from digested lungs; after exclusion of doublets and debris, leukocytes are separated by CD45 staining. CD11c-negative, CD11b-positive, and Ly6c-positive cells are identified on circulating monocytes. On the other hand, CD11c-positive and CD11b-negative cells are identified on alveolar macrophages. The percentages of $\mathbf{c}$ circulating monocytes and $\mathbf{d}$ alveolar macrophages are compared between vehicle- and palmitic acidadministered mice ( $n=6$ in each group). $* * P<0.01$.

(a)

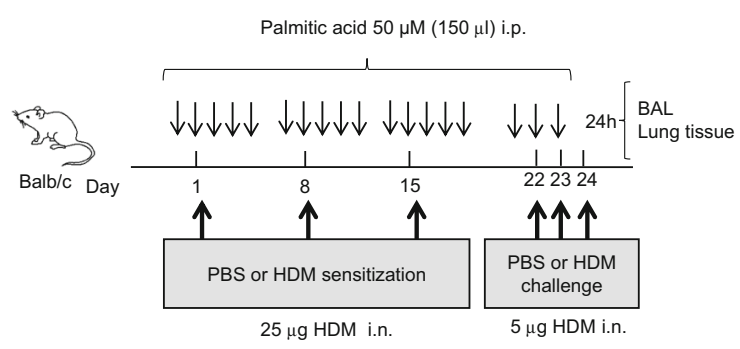

(c)

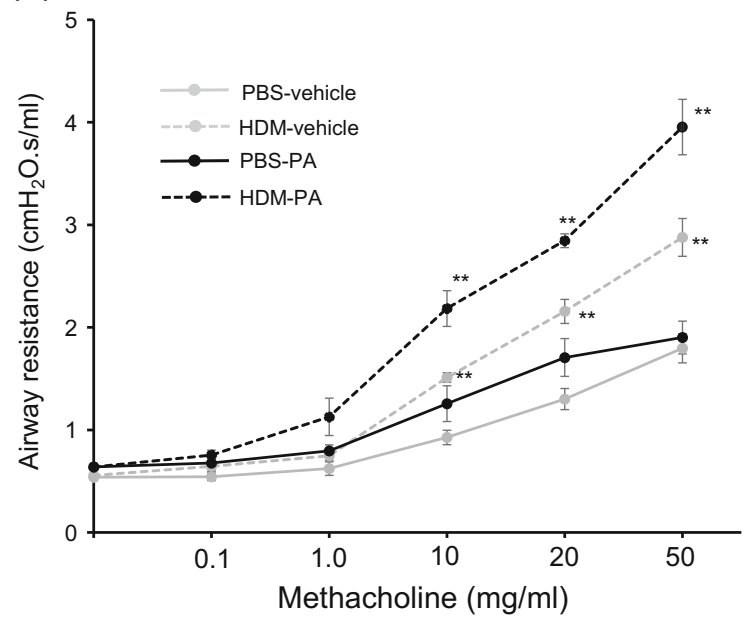

) the best of our knowledge, this was the first report that clarified the augmenting mechanisms of asthma in obesity in relation to SFA and macrophages.

In the present study, lung macrophages, including circulating monocytes and alveolar macrophages, were significantly increased in HFD mice and PA-administered mice, although there was no difference in the number of macrophages in BALF. A previous study reported that the phenotypes of alveolar and interstitial macrophages in

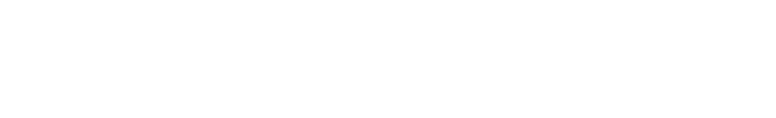

Fig. 5. PA arguments HDM-induced neutrophilic airway inflammation, airway hyperresponsiveness, and cytokine production in the lungs. a Protocol of HDM-induced airway inflammation mouse model administered with vehicle or PA. b Bronchoalveolar lavage fluid total and differential cell counts is compared among PBS-vehicle, HDM-vehicle, PBS-PA, and HDM-PA mice ( $n=6$ in each group). The HDM-vehicle group is compared with the HDM-PA group. c Airway hyperreactivity is assessed by measuring airway resistance according to graded concentrations of methacholine in PBS-vehicle, HDMvehicle, PBS-PA, and HDM-PA mice ( $n=6$ in each group). The HDM-vehicle group is compared with the PBS-vehicle group, while the HDM-PA group is compared with the HDM-vehicle mice. d Histologic examination for airway inflammation. Sections are stained with H \& E (upper panels) and PAS (lower panels). Original magnification was $\times 200$. Concentrations of $\mathbf{e}$ IL-13, f IL-17A, $\mathbf{g ~ I L}-1 \beta$, and $\mathbf{h}$ MIP2 in the lung tissue were measured by ELISA $(n=6$ in each group). ${ }^{*} P<0.05,{ }^{*} P<<0.01$. HDM, house dust mite; $P A$, palmitic acid; $P B S$, phosphate-buffered saline; $H \& E$, hematoxylin and eosin; $P A S$, periodic acid-Schiff; MIP2, macrophage inflammatory protein 2; ELISA, enzyme-linked immunosorbent assay. 
(d)

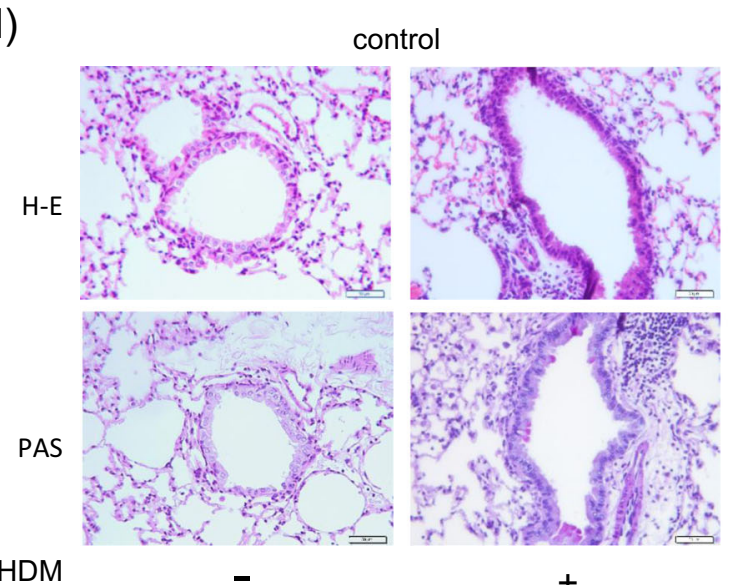

(e)

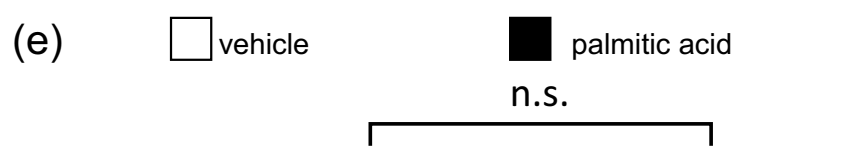

$+$

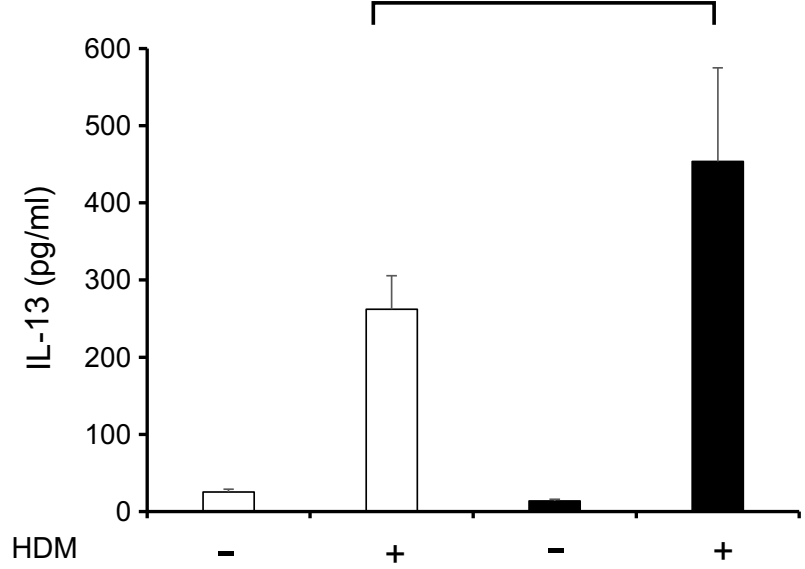

(g)

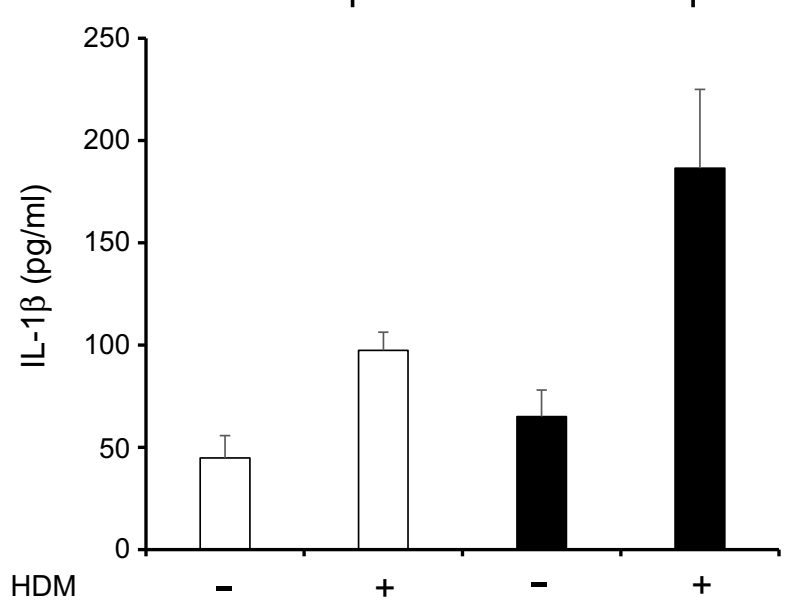

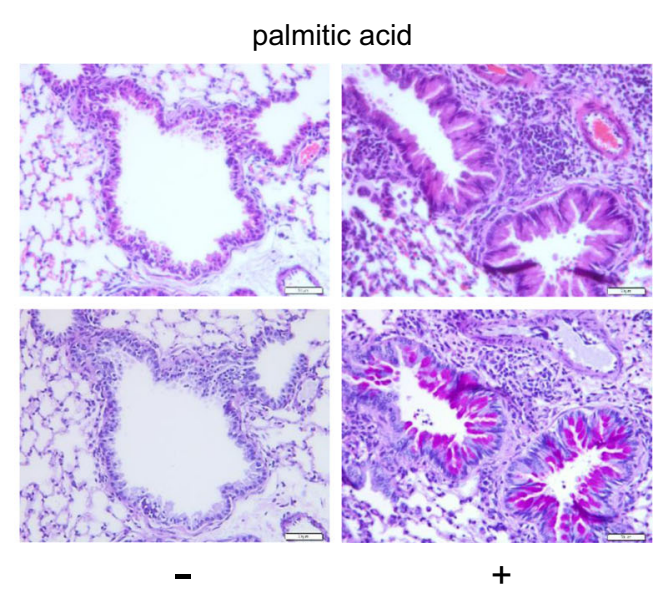

(f)

n.s.

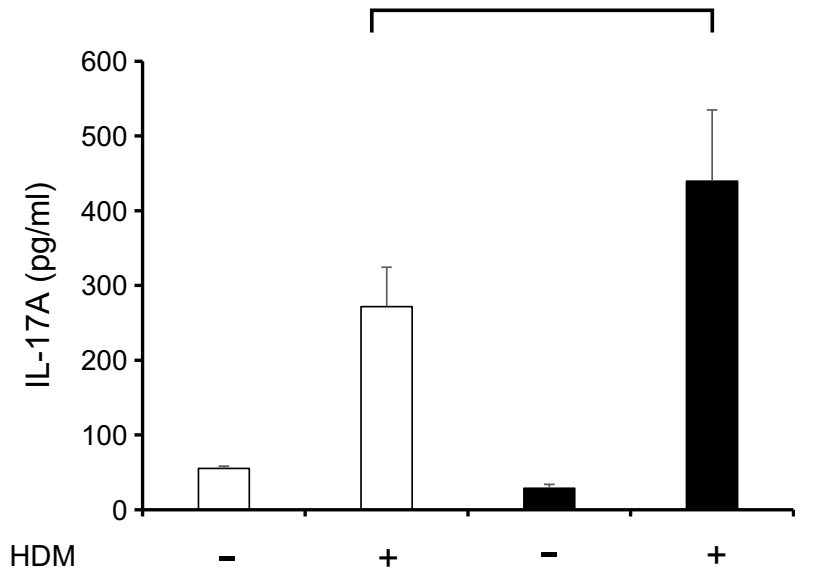

(h)
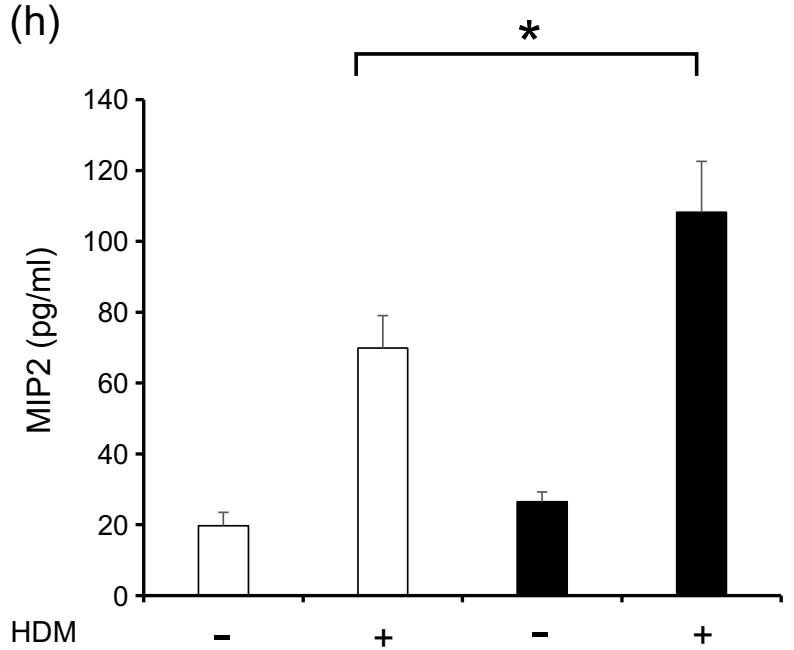

Fig. 5. continued. 
BALF were different from those in lung tissue [51]. We considered that interstitial macrophages might be related to the increasing number of macrophages in lung tissue. Macrophages were reported as pivotal regulators of immunity and inflammation in obesity and asthma [10, 32]. Mcneils et al. reported that obesity increased the recruitment of tissue macrophages and led to inflammation in adipose tissue, liver, and skeletal muscle [25]. Obesity has been shown to regulate macrophage phenotype and to induce inflammatory signals, such as nuclear factor- $\mathrm{kB}$ and phosphatidylinositol 3-kinase [6, 49]. In addition, SFA was shown to modulate TNF- $\alpha$ expression in mice macrophage lineage and to activate inflammation through nucleotide-binding domain, leucine-rich repeats containing family, and pyrin domain-containing-3 inflammasome [9, 44]. Circulating and alveolar macrophages are crucial for airway inflammation and are related to the pathogenesis of severe asthma through LPS responsiveness [19, 31]. We have reported that circulating macrophages, as the source of IL-33, contributed to severe asthma [42]. The findings in this study of increased lung macrophages in HFD mice and PA-administered mice were consistent with those of previous studies.

In the present study, neutrophilic airway inflammation and AHR were augmented along with elevation of MIP2 and IL-17A in the lungs. A previous study reported that asthmatic patients with obesity (BMI $>30$ ) had poor asthma-specific quality of life, poor asthma control, and frequent asthmarelated hospitalizations, compared with non-obese (BMI $<25)$ asthma patients [29]. Recent studies showed that innate lymphoid cell 3-induced IL-17 production was related to obesity-associated AHR through macrophage-derived IL-1 $\beta$ [22] and that blockade of TNF- $\alpha$ attenuated ozone-induced neutrophilic inflammation and AHR in obesity [48]. Additionally, PA induced islet inflammation and recruited macrophages with MCP-1 through TLR4 in vivo [13]. According to these data, we considered that SFA recruited macrophages to the lungs and caused progression of HDM-induced neutrophilic airway inflammation in refractory asthma. This ICSinsensitive phenotype might be a result of IL-17A and MIP2 induction, as demonstrated in this HFD mouse model.

We have shown that PA induced MCP-1 production and exacerbation of LPS-primed inflammatory cytokine production from macrophages. MCP-1 was reported as an obesity-related chemokine that modulates tissue migration of macrophages [30]. In addition, obese patients were shown to express higher plasma levels of MCP-1 than normal patients $[5,7]$. LPS, which is contained in HDM, caused a shift from eosinophilic to neutrophilic airway inflammation, along with elevation of IL-8; these contributed to resistance to asthma treatment $[24,53]$. According to these results, attenuation of SFA levels might control neutrophilic airway inflammation in obese patients with asthma. In the future, reduction of SFA-regulated migration of lung macrophages may be a target of treatment in severe asthma patients with obesity.

In conclusion, SFA induced MCP-1 production for macrophage recruitment to the lungs and directly enhanced LPS-induced TNF- $\alpha$ and IL-1 $\beta$ production by macrophages. Furthermore, SFA increased the number of lung macrophages, augmented HDM-induced neutrophilic airway inflammation and AHR, and increased the levels of IL-17A and MIP2 in HFD mice.

\section{ACKNOWLEDGEMENTS}

We thank Dr. Shinichiro Hayashi of the International University of Health and Welfare, Fukuoka for his critical review of this manuscript.

\section{COMPLIANCE WITH ETHICAL STANDARDS}

Funding. This study was supported by the Researcher Supporting Program of Saga University (KT).

Conflict of Interest. The authors declare that they have no competing interests.

Ethical Approval. All applicable international, national, and/or institutional guidelines for the care and use of animals were followed.

Open Access This article is distributed under the terms of the Creative Commons Attribution 4.0 International License (http://creativecommons.org/licenses/by/ $4.0 /$ ), which permits unrestricted use, distribution, and reproduction in any medium, provided you give appropriate credit to the original author(s) and the source, provide a link to the Creative Commons license, and indicate if changes were made.

\section{REFERENCES}

1. Accordini, S., A.G. Corsico, M. Braggion, M.W. Gerbase, D. Gislason, A. Gulsvik, J. Heinrich, et al. 2013. The cost of persistent asthma in Europe: An international population-based study in adults. International Archives of Allergy and Immunology 160 (1): 93-101. doi:10.1159/000338998. 
2. Barnett, S.B., and T.A. Nurmagambetov. 2011. Costs of asthma in the United States: 2002-2007. The Journal of Allergy and Clinical Immunology 127 (1): 145-152. doi:10.1016/j.jaci.2010.10.020.

3. Beuther, D.A., and E.R. Sutherland. 2007. Overweight, obesity, and incident asthma: A meta-analysis of prospective epidemiologic studies. American Journal of Respiratory and Critical Care Medicine 175 (7): 661-666. doi:10.1164/rccm.200611-1717OC.

4. Boulet, L.P., and E. Franssen. 2007. Influence of obesity on response to fluticasone with or without salmeterol in moderate asthma. Respiratory Medicine 101 (11): 2240-2247. doi:10.1016/ j.rmed.2007.06.031.

5. Breslin, W.L., C.A. Johnston, K. Strohacker, K.C. Carpenter, T.R. Davidson, J.P. Moreno, J.P. Foreyt, and B.K. McFarlin. 2012. Obese Mexican American children have elevated MCP-1, TNF-alpha, monocyte concentration, and dyslipidemia. Pediatrics 129 (5): e1180-e1186. doi:10.1542/peds.2011-2477.

6. Castoldi, A., C. Naffah de Souza, N.O. Camara, and P.M. MoraesVieira. 2015. The macrophage switch in obesity development. Frontiers in Immunology 6: 637. doi:10.3389/fimmu.2015.00637.

7. Catalan, V., J. Gomez-Ambrosi, B. Ramirez, F. Rotellar, C. Pastor, C. Silva, A. Rodriguez, M.J. Gil, J.A. Cienfuegos, and G. Fruhbeck. 2007. Proinflammatory cytokines in obesity: Impact of type 2 diabetes mellitus and gastric bypass. Obesity Surgery 17 (11): 1464-1474.

8. Chung, K.F., S.E. Wenzel, J.L. Brozek, A. Bush, M. Castro, P.J. Sterk, I.M. Adcock, et al. 2014. International ERS/ATS guidelines on definition, evaluation and treatment of severe asthma. The European Respiratory Journal 43 (2): 343-373. doi:10.1183/ 09031936.00202013.

9. de Lima-Salgado, T.M., T.C. Alba-Loureiro, C.S. do Nascimento, M.T. Nunes, and R. Curi. 2011. Molecular mechanisms by which saturated fatty acids modulate TNF-alpha expression in mouse macrophage lineage. Cell Biochemistry and Biophysics 59 (2): 8997. doi:10.1007/s12013-010-9117-9.

10. Diaz, J., L. Warren, L. Helfner, X. Xue, P.K. Chatterjee, M. Gupta, M.H. Solanki, M. Esposito, V. Bonagura, and C.N. Metz. 2015. Obesity shifts house dust mite-induced airway cellular infiltration from eosinophils to macrophages: Effects of glucocorticoid treatment. Immunologic Research 63 (1-3): 197-208. doi:10.1007/ s12026-015-8717-2.

11. Dixon, A.E., R.E. Pratley, P.M. Forgione, D.A. Kaminsky, L.A. Whittaker-Leclair, L.A. Griffes, J. Garudathri, et al. 2011. Effects of obesity and bariatric surgery on airway hyperresponsiveness, asthma control, and inflammation. The Journal of Allergy and Clinical Immunology 128 (3): 508-515 . doi:10.1016/ j.jaci.2011.06.009.e501-502

12. Dixon, A.E., M. Subramanian, M. DeSarno, K. Black, L. Lane, and F. Holguin. 2015. A pilot randomized controlled trial of pioglitazone for the treatment of poorly controlled asthma in obesity. Respiratory Research 16: 143. doi:10.1186/s12931-015-0303-6.

13. Eguchi, K., I. Manabe, Y. Oishi-Tanaka, M. Ohsugi, N. Kono, F. Ogata, N. Yagi, et al. 2012. Saturated fatty acid and TLR signaling link beta cell dysfunction and islet inflammation. Cell Metabolism 15 (4): 518-533. doi:10.1016/j.cmet.2012.01.023.

14. Fahy, J.V. 2015. Type 2 inflammation in asthma - present in most, absent in many. Nature Reviews. Immunology 15 (1): 57-65. doi:10.1038/nri3786.

15. Finucane, O.M., C.L. Lyons, A.M. Murphy, C.M. Reynolds, R. Klinger, N.P. Healy, A.A. Cooke, et al. 2015. Monounsaturated fatty acid-enriched high-fat diets impede adipose NLRP3 inflammasomemediated IL-1beta secretion and insulin resistance despite obesity. Diabetes 64 (6): 2116-2128. doi:10.2337/db14-1098.

16. Fukuno, Y., S. Hayashi, K. Kohsa, N. Fujisawa, M. Tominaga, E.J. Miller, and K. Nagasawa. 2003. Chemokine receptor inhibitor, antileukinate, suppressed ovalbumin-induced eosinophilic inflammation in the airway. Cytokine 22 (5): 116-125.

17. Glass, C.K., and J.M. Olefsky. 2012. Inflammation and lipid signaling in the etiology of insulin resistance. Cell Metabolism 15 (5): 635-645. doi:10.1016/j.cmet.2012.04.001.

18. Hellmann, J., M.J. Zhang, Y. Tang, M. Rane, A. Bhatnagar, and M. Spite. 2013. Increased saturated fatty acids in obesity alter resolution of inflammation in part by stimulating prostaglandin production. Journal of Immunology 191 (3): 1383-1392. doi:10.4049/ jimmunol.1203369.

19. Huynh, M.L., K.C. Malcolm, C. Kotaru, J.A. Tilstra, J.Y. Westcott, V.A. Fadok, and S.E. Wenzel. 2005. Defective apoptotic cell phagocytosis attenuates prostaglandin E2 and 15-hydroxyeicosatetraenoic acid in severe asthma alveolar macrophages. American Journal of Respiratory and Critical Care Medicine 172 (8): 972-979. doi:10.1164/recm.200501-035OC.

20. Julia, V., L. Macia, and D. Dombrowicz. 2015. The impact of diet on asthma and allergic diseases. Nature Reviews. Immunology 15 (5): 308-322. doi: $10.1038 /$ nri3830.

21. Kato, G., K. Takahashi, H. Tashiro, K. Kurata, H. Shirai, S. Kimura, and S. Hayashi. 2014. beta2 adrenergic agonist attenuates house dust mite-induced allergic airway inflammation through dendritic cells. BMC Immunology 15: 39. doi:10.1186/s12865-014-0039-y.

22. Kim, H.Y., H.J. Lee, Y.J. Chang, M. Pichavant, S.A. Shore, K.A. Fitzgerald, Y. Iwakura, et al. 2014. Interleukin-17-producing innate lymphoid cells and the NLRP3 inflammasome facilitate obesityassociated airway hyperreactivity. Nature Medicine 20 (1): 54-61. doi: $10.1038 / \mathrm{nm} .3423$.

23. Lambrecht, B.N., and H. Hammad. 2015. The immunology of asthma. Nature Immunology 16 (1): 45-56. doi:10.1038/ni.3049.

24. Leaker, B.R., P.J. Barnes, and B. O'Connor. 2013. Inhibition of LPSinduced airway neutrophilic inflammation in healthy volunteers with an oral CXCR2 antagonist. Respiratory Research 14: 137. doi:10.1186/1465-9921-14-137.

25. McNelis, J.C., and J.M. Olefsky. 2014. Macrophages, immunity, and metabolic disease. Immunity 41 (1): 36-48. doi:10.1016/ j.immuni.2014.05.010.

26. Moon, M.L., J.J. Joesting, M.A. Lawson, G.S. Chiu, N.A. Blevins, K.A. Kwakwa, and G.G. Freund. 2014. The saturated fatty acid, palmitic acid, induces anxiety-like behavior in mice. Metabolism 63 (9): 1131-1140. doi:10.1016/j.metabol.2014.06.002.

27. Moore, W.C., E.R. Bleecker, D. Curran-Everett, S.C. Erzurum, B.T. Ameredes, L. Bacharier, W.J. Calhoun, et al. 2007. Characterization of the severe asthma phenotype by the National Heart, Lung, and Blood Institute's Severe Asthma Research Program. The Journal of Allergy and Clinical Immunology 119 (2): 405-413. doi:10.1016/ j.jaci.2006.11.639.

28. Moore, W.C., D.A. Meyers, S.E. Wenzel, W.G. Teague, H. Li, X. Li, R. D'Agostino Jr., et al. 2010. Identification of asthma phenotypes using cluster analysis in the Severe Asthma Research Program. American Journal of Respiratory and Critical Care Medicine 181 (4): 315-323. doi:10.1164/rccm.200906-0896OC.

29. Mosen, D.M., M. Schatz, D.J. Magid, and C.A. Camargo Jr. 2008. The relationship between obesity and asthma severity and control in adults. The Journal of Allergy and Clinical Immunology 122 (3): 507-511 . doi:10.1016/j.jaci.2008.06.024.e506

30. Panee, J. 2012. Monocyte chemoattractant protein 1 (MCP-1) in obesity and diabetes. Cytokine 60 (1): 1-12. doi:10.1016/ j.cyto.2012.06.018.

31. Pappas, K., A.I. Papaioannou, K. Kostikas, and N. Tzanakis. 2013. The role of macrophages in obstructive airways disease: Chronic obstructive pulmonary disease and asthma. Cytokine 64 (3): 613625. doi:10.1016/j.cyto.2013.09.010. 
32. Periyalil, H.A., L.G. Wood, H.A. Scott, M.E. Jensen, and P.G. Gibson. 2015. Macrophage activation, age and sex effects of immunometabolism in obese asthma. The European Respiratory Journal 45 (2): 388-395. doi:10.1183/09031936.00080514.

33. Peters-Golden, M., A. Swern, S.S. Bird, C.M. Hustad, E. Grant, and J.M. Edelman. 2006. Influence of body mass index on the response to asthma controller agents. The European Respiratory Journal 27 (3): 495-503. doi:10.1183/09031936.06.00077205.

34. Peters, M.C., and J.V. Fahy. 2016. Metabolic consequences of obesity as an "outside in" mechanism of disease severity in asthma. The European Respiratory Journal 48 (2): 291-293. doi:10.1183/ 13993003.01132-2016.

35. Ray, A., M. Raundhal, T.B. Oriss, P. Ray, and S.E. Wenzel. 2016. Current concepts of severe asthma. The Journal of Clinical Investigation 126 (7): 2394-2403. doi:10.1172/JCI84144.

36. Rocha, D.M., A.P. Caldas, L.L. Oliveira, J. Bressan, and H.H. Hermsdorff. 2016. Saturated fatty acids trigger TLR4-mediated inflammatory response. Atherosclerosis 244: 211-215. doi:10.1016/j.atherosclerosis.2015.11.015.

37. Ruiz-Nunez, B., D.A. Dijck-Brouwer, and F.A. Muskiet. 2016. The relation of saturated fatty acids with low-grade inflammation and cardiovascular disease. The Journal of Nutritional Biochemistry 36: 1-20. doi:10.1016/j.jnutbio.2015.12.007.

38. Shore, S.A., and Y. Cho. 2016. Obesity and asthma: Microbiomemetabolome interactions. American Journal of Respiratory Cell and Molecular Biology 54 (5): 609-617. doi:10.1165/rcmb.20160052PS.

39. Sutherland, E.R., E. Goleva, M. Strand, D.A. Beuther, and D.Y. Leung. 2008. Body mass and glucocorticoid response in asthma. American Journal of Respiratory and Critical Care Medicine 178 (7): 682-687. doi:10.1164/rccm.200801-076OC.

40. Takahashi, K., K. Koga, H.M. Linge, Y. Zhang, X. Lin, C.N. Metz, Y. Al-Abed, K. Ojamaa, and E.J. Miller. 2009. Macrophage CD74 contributes to MIF-induced pulmonary inflammation. Respiratory Research 10: 33. doi:10.1186/1465-9921-10-33.

41. Takahashi, K., T. Shibata, S. Akashi-Takamura, T. Kiyokawa, Y. Wakabayashi, N. Tanimura, T. Kobayashi, et al. 2007. A protein associated with Toll-like receptor (TLR) 4 (PRAT4A) is required for TLR-dependent immune responses. The Journal of Experimental Medicine 204 (12): 2963-2976. doi:10.1084/jem.20071132.

42. Tashiro, H., K. Takahashi, S. Hayashi, G. Kato, K. Kurata, S. Kimura, and N. Sueoka-Aragane. 2016. Interleukin-33 from monocytes recruited to the lung contributes to house dust mite-induced airway inflammation in a mouse model. PloS One 11 (6): e 0157571. doi:10.1371/journal.pone.0157571.
43. Welty, F.K., A. Alfaddagh, and T.K. Elajami. 2016. Targeting inflammation in metabolic syndrome. Translational Research 167 (1): 257-280. doi:10.1016/j.trsl.2015.06.017.

44. Wen, H., D. Gris, Y. Lei, S. Jha, L. Zhang, M.T. Huang, W.J. Brickey, and J.P. Ting. 2011. Fatty acid-induced NLRP3-ASC inflammasome activation interferes with insulin signaling. Nature Immunology 12 (5): 408-415. doi:10.1038/ni.2022.

45. Wensveen, F.M., S. Valentic, M. Sestan, T. Turk Wensveen, and B. Polic. 2015. The "Big Bang" in obese fat: Events initiating obesityinduced adipose tissue inflammation. European Journal of Iтmиnology 45 (9): 2446-2456. doi:10.1002/eji.201545502.

46. Wenzel, S. 2012. Severe asthma: From characteristics to phenotypes to endotypes. Clinical and Experimental Allergy 42 (5): 650-658. doi:10.1111/j.1365-2222.2011.03929.x.

47. Wijesinghe, M., M. Weatherall, K. Perrin, J. Crane, and R. Beasley. 2009. International trends in asthma mortality rates in the 5- to 34year age group: A call for closer surveillance. Chest 135 (4): 1045 1049. doi:10.1378/chest.08-2082.

48. Williams, A.S., J.A. Mathews, D.I. Kasahara, A.P. Wurmbrand, L. Chen, and S.A. Shore. 2015. Innate and ozone-induced airway hyperresponsiveness in obese mice: Role of TNF-alpha. American Journal of Physiology. Lung Cellular and Molecular Physiology 308 (11): L1168-L1177. doi:10.1152/ajplung.00393.2014.

49. Wynn, T.A., and L. Barron. 2010. Macrophages: Master regulators of inflammation and fibrosis. Seminars in Liver Disease 30 (3): 245257. doi:10.1055/s-0030-1255354.

50. Xiu, F., L. Diao, P. Qi, M. Catapano, and M.G. Jeschke. 2016. Palmitate differentially regulates the polarization of differentiating and differentiated macrophages. Immunology 147 (1): 82-96. doi:10.1111/imm. 12543 .

51. Zaynagetdinov, R., T.P. Sherrill, P.L. Kendall, B.H. Segal, K.P. Weller, R.M. Tighe, and T.S. Blackwell. 2013. Identification of myeloid cell subsets in murine lungs using flow cytometry. American Journal of Respiratory Cell and Molecular Biology 49 (2): 180 189. doi:10.1165/remb.2012-0366MA.

52. Zhao, L., S. Zhong, H. Qu, Y. Xie, Z. Cao, Q. Li, P. Yang, et al. 2015. Chronic inflammation aggravates metabolic disorders of hepatic fatty acids in high-fat diet-induced obese mice. Scientific Reports 5: 10222. doi:10.1038/srep10222.

53. Zhao, S., Y. Jiang, X. Yang, D. Guo, Y. Wang, J. Wang, R. Wang, and C. Wang. 2016. Lipopolysaccharides promote a shift from Th2derived airway eosinophilic inflammation to Th17-drived neutrophilic inflammation in an ovalbumin-sensitized murine asthma model. Journal of Asthma. doi:10.1080/02770903.2016.1223687. 